\title{
The Influence of Natural Vitamin C on Broiler Chickens Haematological and Economical Parameters
}

\author{
Laura CĂTANĂ*, Cristina ŞTEFĂNUȚ, Raul CĂTANĂ, Anca CHEREJI, Mihai CERNEA \\ University of Agricultural Sciences and Veterinary Medicine Cluj-Napoca \\ *Corresponding author: drv_catanalaura@yahoo.com
}

Bulletin UASVM Veterinary Medicine 72(2) / 2015,

Print ISSN 1843-5270; Electronic ISSN 1843-5378

DOI:10.15835/buasvmcn-vm: 11318

\begin{abstract}
The study was designed to determine the efficacy of a phytotherapeutical product rich in natural vitamin C over the feed intake in broiler chickens. The testing was performed on 20 broilers, divided in 2 groups: group I, control, and group II, experimental, containing broilers which have received an additional intake of phytotherapeutical product. During the assessment period all the data regarding the haematological tests, the amount of forage, the individual weight at 1,9 and 56 days and the carcass weight were registered. At 56 days the average weight for group II was $2900 \mathrm{~g}$ compared to the first group which had an average weight of $2615 \mathrm{~g}$. The natural vitamin C determined a superior valorisation of the nutritional principles found in feed, the average carcass weight difference being of $410 \mathrm{~g}$ in favour of the group II, an increase of $23.4 \%$ compared to control group. The slaughter yield was in average $74.48 \%$ for group II and $66.92 \%$ for group I. The average feed conversion ratio showed that for $1 \mathrm{~kg}$ of body mass gain, the average feed consumption was $1434 \mathrm{~g}$ for group I and $1621 \mathrm{~g}$ for group II. Compared to control group, in the group II, at 56 days, the haematological parameters reached optimal levels, the average WBC count being 23.00 $\mathrm{G} / \mathrm{L}$, the RBC count $2.92 \mathrm{~T} / \mathrm{L}$ and the haematocrit $32.60 \%$. The assessed data showed a positive effect of the natural vitamin $\mathrm{C}$ phytotherapeutical product on the haematological parameters and on the economical parameters.
\end{abstract}

Keywords: broiler chickens, economical parameters, natural vitamin $C$

\section{INTRODUCTION}

The combination of natural vitamin $\mathrm{C}$ and bioflavonoids is essential for the vitamin's proper absorption and for maintaining tissue integrity. They work as antioxidants, increasing the capillary resistance and regularizing their permeability, preventing the ruptures and providing protection against infections (Tarwadi and Agte, 2007; Cernea, 2009; Ruiz-Feria, 2009; Cernea, 2011). Somogyi JC was the first to present a mechanism for the effect of bioflavonoids on vitamin $C$ in the physiological fluids. He hypothesised that flavonoids act as sparing factors in slowing down the oxidation of Vitamin C. This antioxidant effect was shown by in vitro studies with oxidants such as ascorbic acid oxidase, copper and peroxidase (Weseler and Bast, 2012). Vitamin C lowers the incidence of pulmonary hypertension syndrome and the associated muscularisation of pulmonary arterioles induced by exposing broilers to cool environmental temperatures and can offer a good management practice in laying hens reared at high temperatures (Sahin et al., 2002; Xiang et al., 2002).

\section{MATERIALS AND METHODS}

The study aimed to determine the intake efficacy of an Indian veterinary phytotherapeutical commercial product, rich in natural vitamin $\mathrm{C}$, consisting of the following plant extracts: 55\% Emblica officinalis (Indian gooseberry), 14\% Citrus limonum (lemon), 14\% Citrus sinensis (orange), 8\% Lycopersicon esculentum (tomato), 4\% Psidium Guajava (guava), 3\% Carica papaya 
(papaya), 2\% Mangifera indica (mango). The final quantity of vitamin C was $180 \mathrm{~g}$ per litre of product.

All assessments were performed in 57 days, between January and February 2014, on 20 Cobb 500 broiler chickens.

In the beginning, the one day old subjects were separated in two experimental groups: group I the control group, consisting of 10 broiler chickens which received phytotherapeutical product free drinking water; group II, the experimental group, consisting of 10 broiler chickens, which received an additional intake of phytotherapeutical product with natural vitamin $\mathrm{C}$, at a dosage of $1 \mathrm{ml}$ product per litre of drinking water.

From each chicken, blood samples for haematological tests were collected at the beginning and at the end of the experiment. During the assessment period, all the data regarding the amount of forage, individual weight at 1, 9 and 56 days and carcass weight were recorded.

Chickens, in both groups, received ad libitum an equal daily amount of commercial feed. The feed's composition was: maize $=45.55 \%$, wheat $=12.35 \%$, soy scraps $=31 \%$, sunflower oil $=$ $5.2 \%$, growth premix $=0.5 \%$, fish flour $(67 \%$ protein) $=2 \%$, coccidiostatic $=0.05 \%$, calcium $=1.25 \%$, phosphate $=1.45 \%$, salt $=0.25 \%$, methionine $=0.1 \%$, mycotoxins inhibitor $=0.1 \%$, immunostimulant $=0.1 \%$, lysine $=0.1 \%$.

The haematological tests performed were: Leukocyte Count (WBC count), Red blood cells (RBC count), Haemoglobin (Hb), Hematocrit $(\mathrm{Ht})$, Mean corpuscular volume (MCV), Mean corpuscular haemoglobin (MCH), Mean corpuscular haemoglobin concentration (MCHC).

The results assessment and interpretation were made with the GraphPad In Stat program (Motulsky HJ, 2004), using The Dunnett Multiple Comparisons Test. The statistical validity of test data was achieved by applying normality tests using Kolmogorov-Smirnov index calculation. In all calculated and compared variants, results passed the normality tests, being considered accurate, and the used database having sufficient variables (significance level of 0.05 ).

At the end of each day, the amount of unconsumed feed was weighed, thus obtaining the amount of forage consumed per $24 \mathrm{~h}$ and per group. During the 57 days of the experiment, 3 individual weighings were made: on day 1, day 9 and day 56, using a digital scale with an accuracy of +/- 1 gram.

\section{RESULTS AND DISCUSSION}

In both groups, haematological parameters from day 1 through, to day 56, were within the normal limits of the species.

On day 56, the average haematological parameters differences were statistically significant for: WBC count, RBC count and Haematocrit, in favour of the second group. The average Haemoglobin results had a highly significant difference in favour of group II.

In group II, at 56 days, the WBC count showed an increase, from the mean value of $18.00 \mathrm{G} / \mathrm{L}$ in day 1 to 23G/L in day 56. The phenomenon was also noted in the control group, but with a significantly lower increase.

The RBC count values also revealed significant differences between the two groups, group II having a mean value of $2.92 \mathrm{~T} / \mathrm{L}$ on day 56 while group I underwent a decrease in the total number of erythrocytes from the mean value of $2.65 \mathrm{~T} / \mathrm{L}$ on day 1 to $2.49 \mathrm{~T} / \mathrm{L}$ at the end of the experiment.

The assessment of total haemoglobin revealed a slight increase in both groups. Nevertheless, the values were maintained within the normal limits.

The haematocrit measurements $(\mathrm{Ht})$ revealed a mean increase of $6.4 \%$ in group II, with a

Tab. 1. Average haematological parameters assessed on day 1 for both experimental groups

\begin{tabular}{|c|c|c|c|c|c|c|c|c|}
\hline & Parameter & WBC count $(\mathrm{G} / \mathrm{L})$ & $\begin{array}{c}\text { RBC count } \\
(\mathrm{T} / \mathrm{L})\end{array}$ & $\begin{array}{l}\text { Haemoglobin } \\
(\mathrm{g} / \mathrm{dl})\end{array}$ & $\begin{array}{c}\text { Haematocrit } \\
(\%)\end{array}$ & MCV (fl) & $\begin{array}{c}\mathrm{MCH} \\
(\mathrm{pg}) \\
\end{array}$ & $\begin{array}{l}\text { MCHC } \\
(\mathrm{g} / \mathrm{dl}) \\
\end{array}$ \\
\hline \multirow{2}{*}{ Group I } & Mean & 16.50 & 2.65 & 6.77 & 28.00 & 108.12 & 25.83 & 24.72 \\
\hline & $\mathrm{SD}(\sigma)$ & 2.429 & 0.331 & 0.354 & 5.241 & 22.895 & 3.340 & 5.610 \\
\hline \multirow{3}{*}{ Group II } & Mean & 18.00 & 2.59 & 7.55 & 26.20 & 103.72 & 29.35 & 30.03 \\
\hline & $\mathrm{SD}(\sigma)$ & 6.022 & 0.382 & 0.772 & 5.083 & 30.147 & 2.451 & 7.985 \\
\hline & $\mathrm{p}$ & 0,33 & 0,38 & $0,024^{*}$ & 0,24 & 0,39 & $0,03^{*}$ & 0,1 \\
\hline
\end{tabular}


statistically significant difference between the two groups.

The mean corpuscular volume (MCV) displayed increases in both groups, but with values within the normal limits. Mean corpuscular haemoglobin $(\mathrm{MCH})$, had an average decrease of $1 \mathrm{pg}$ in group II in comparison with the day 1 results. Conversely, the control group had a 3.35 pg average decrease.

In group II, MCHC underwent an average decrease of $4.56 \mathrm{~g} / \mathrm{dl}$ on day 56 compared to day 1 . In the control group an average increase of $0.74 \mathrm{~g} /$ dl was noted. Regardless of the MCHC variations, in the two groups, they remained within the physiological limits of the species (between 26 to $35 \mathrm{~g} / \mathrm{dl}$ ) with no statistically significant difference $(\mathrm{p}=0,33)$.

All haematological data analyses revealed that additional administration of the vitamin $\mathrm{C}$ rich phytotherapeutical product had no negative effects on the broiler chickens health status, furthermore, the haematological parameters reached optimal levels.

In terms of body weight dynamics, chickens in the control group had an average body weight of $55.9 \mathrm{~g}$ on day 1 , reaching $253.7 \mathrm{~g}$ on day 9 and
$2615 \mathrm{~g}$ on day 56 (Fig. 1). The average daily gain of the control group was $45.69 \mathrm{~g}$.

In the experimental group (II) the average body weight was insignificantly increased on day 9, compared to the average body weight of group I. However, on day 56, the average body weight of the group reached $2900 \mathrm{~g}$, with an individual maximum of $3000 \mathrm{~g}$. Therefore, a substantial weight increase was noticed in the experimental group II, especially towards the end of the experiment, the body weight being, in average, with $285 \mathrm{~g}$ higher than the average of the control group.

The average daily gain calculated for the first nine days was $21.98 \mathrm{~g}$ in group I and $22.07 \mathrm{~g}$ in group II. For the next 47 days, the average daily gain was $50.24 \mathrm{~g}$ in group I and $56.7 \mathrm{~g}$ for group II.

In terms of the carcass weight (Fig. 2), the control group had an average carcass weight of $1750 \mathrm{~g}$, with an individual minimum of $1600 \mathrm{~g}$ and a maximum of $1900 \mathrm{~g}$. The poultry carcasses of group II had an average carcass weight of 2160 $\mathrm{g}$, with a minimum of $2100 \mathrm{~g}$ and a maximum of $2200 \mathrm{~g}$.

The average carcass weight difference between the groups was $410 \mathrm{~g}$ in favour of group II, representing an increase of $23.4 \%$ compared to

Tab. 2. Average haematological parameters assessed on day 56 for both experimental groups

\begin{tabular}{|c|c|c|c|c|c|c|c|c|}
\hline & Parameter & $\begin{array}{c}\text { WBC count } \\
(\mathrm{G} / \mathrm{L})\end{array}$ & $\begin{array}{l}\text { RBC count } \\
(\mathrm{T} / \mathrm{L})\end{array}$ & $\begin{array}{l}\text { Haemoglobin } \\
(\mathrm{g} / \mathrm{dl})\end{array}$ & $\begin{array}{c}\text { Haematocrit } \\
(\%)\end{array}$ & $\operatorname{MCV}(\mathrm{fl})$ & $\begin{array}{c}\mathrm{MCH} \\
(\mathrm{pg})\end{array}$ & $\begin{array}{l}\text { MCHC } \\
(\mathrm{g} / \mathrm{dl})\end{array}$ \\
\hline \multirow{2}{*}{ Group I- } & Mean & 17.00 & 2.49 & 7.23 & 27.50 & 112.51 & 29.18 & 26.45 \\
\hline & $\mathrm{SD}(\sigma)$ & 3.545 & 0.335 & 0.279 & 4.231 & 23.085 & 4.345 & 4.058 \\
\hline \multirow{3}{*}{ Group II } & Mean & 23.00 & 2.92 & 8.21 & 32.60 & 113.01 & 28.35 & 25.46 \\
\hline & $\operatorname{SD}(\sigma)$ & 6.512 & 0.292 & 0.605 & 3.559 & 16.927 & 3.190 & 3.976 \\
\hline & $\mathrm{p}$ & $0,04^{*}$ & $0,02^{*}$ & $0,001^{* *}$ & $0,02^{*}$ & 0,48 & 0,35 & 0,33 \\
\hline
\end{tabular}

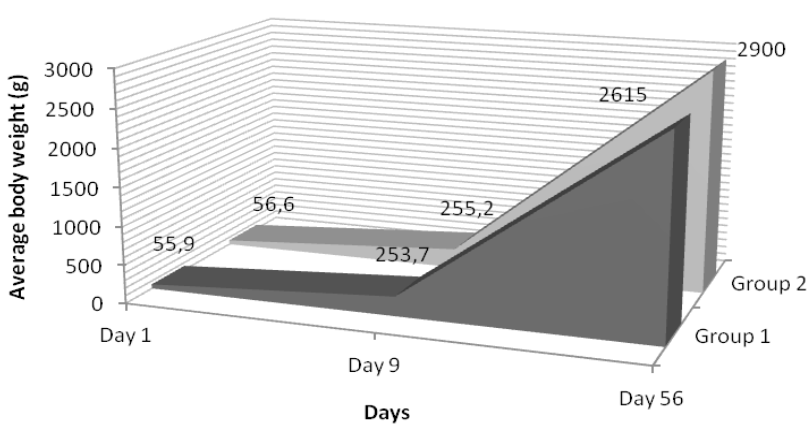

Fig. 1. Average body weight dynamics between day 1 and day 56 in both groups

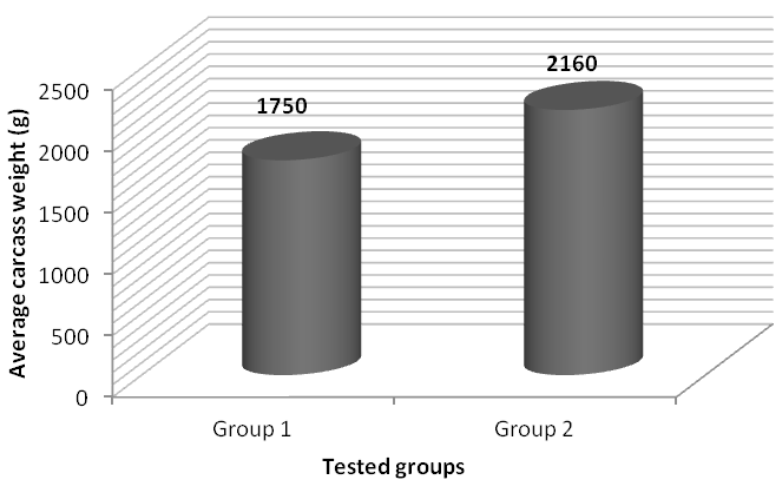

Fig. 2. The comparative values of average carcass weight in the two experimental groups 


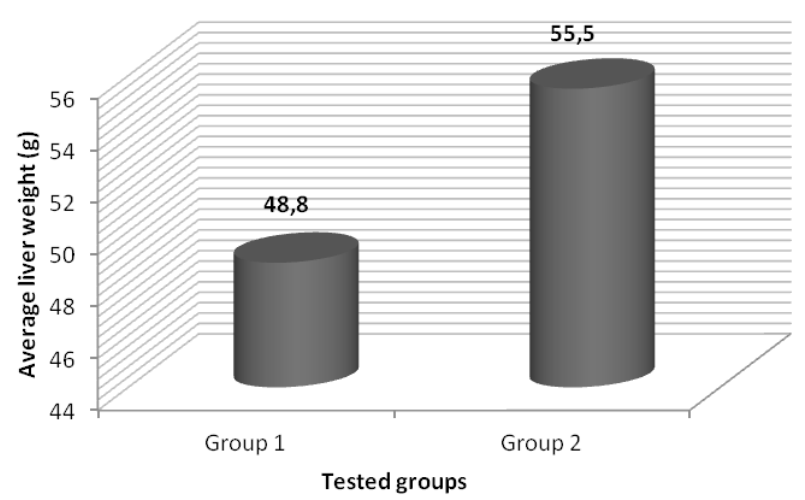

Fig. 3. Comparative values of the average liver weight in the two experimental groups

the broiler chickens of the control group. These results prove the role played by vitamin $C$ in the superior valorisation of the nutrients found in the feed.

Due to superior feed valorisation, group II, which received natural vitamin $\mathrm{C}$ in the drinking water, had a slaughter yield of $74.48 \%$, compared to the one obtained in the control group, which reached only $66.92 \%$. The difference between the two groups is obvious $(7.56 \mathrm{~g})$, significantly less than the breed standard $(77.41 \%)$ due to continuing the experiment for more than 42 days.

Considering that the liver is the body's physiological vitamin C „reservoir”, we determined the liver weight at slaughtering (Fig. 3), pointing out that the control group had an average liver weight of $48.8 \mathrm{~g}$, with a minimum of $45 \mathrm{~g}$ and a maximum of $53 \mathrm{~g}$, while the average liver weight in group II was $55 \mathrm{~g}$, at an average difference of $6.7 \mathrm{~g}$ compared to the control group. These results confirm that the vitamin $\mathrm{C}$ contained in the phytotherapeutical product was highly assimilated and metabolized by the liver.

The average feed consumption, during the experimental period of 56 days, had a value of 3750 $\mathrm{g}$ in the control group, respectively of $4700 \mathrm{~g}$ in the experimental group (Fig. 4). The feed conversion ratio showed that for $1 \mathrm{~kg}$ of body mass gain the feed consumption was of $1621 \mathrm{~g}$ for group II and $1434 \mathrm{~g}$ for group I, phenomenon explained by the increase of the appetite.

Furthermore, this feed conversion rate is explained by the increased size of the liver in chickens thatreceived natural vitamin C. All positive results obtained are attributable to the active

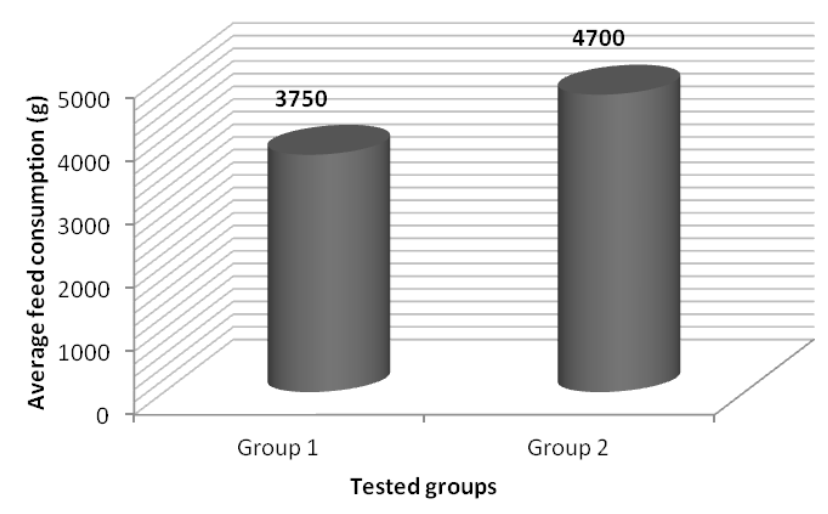

Fig. 4. The average feed consumption in the two experimental groups

principles contained by the phytotherapeutical product.

\section{CONCLUSION}

The continuous administration of the phytotherapeutical product for 56 days optimized the haematological parameters in the experimental group II, compared to the control group.

The phytotherapeutical product triggered a substantial weight increase, especially towards the end of the experiment, with a greater feed conversion ratio in the experimental group, compared to the control group.

The natural vitamin $\mathrm{C}$ found in the phytotherapeutical product led to a superior capitalization of nutrients, an increase of the average carcass weight, of the average daily gain and of the slaughter yield, compared to the control group.

\section{REFERENCES}

1. Cernea Laura Cristina (2009). Analysis models in experimental phytotherapy. AcademicPres, Cluj-Napoca.

2. Cernea Mihai (2011). Pharmacological bases of veterinary therapeutics. Second Edition. AcademicPres, Cluj-Napoca.

3. Motulsky HJ (2004). Analyzing data with GraphPad prism. GraphPad Software Inc USA.

4. Ruiz-Feria CA (2009). Concurrent supplementation of arginine, vitamin $\mathrm{E}$, and vitamin $\mathrm{C}$ improve cardiopulmonary performance in broilers chickens. Poultry Science 88(3):526-535.

5. Sahin K, Sahin N, Sema Yaralioglu (2002). Effects of vitamin $\mathrm{C}$ and vitamin $\mathrm{E}$ on lipid peroxidation, blood serum metabolites, and mineral concentrations of laying hens reared at high ambient temperature. Biological Trace Element Research 85(1):35-45. 
6. Tarwadi Kirtan, Agte V (2007). Antioxidant and micronutrient potential of common fruits available in the Indian subcontinent. Int J Food Sci Nutr 58(5):341-349.

7. Weseler Antje R, Aalt Bast (2012). Pleiotropic-acting nutrients require integrative investigational approaches: the example of flavonoids. Journal of agricultural and food chemistry 60(36):8941-8946.

8. Xiang RP, Sun WD,. Wang JY, Wang XL (2002). Effect of Vitamin $\mathrm{C}$ on pulmonary hypertension and muscularisation of pulmonary arterioles in broilers. British Poultry Science 43(5):705-712. 